\title{
INFLUÊNCIA DOS OCEANOS PACÍFICO E ATLÂNTICO TROPICAIS SOBRE OS ÍNDICES CLIMÁTICOS DA PRECIPITAÇÃO NA BACIA DO SUBMÉDIO SÃO FRANCISCO
}

\author{
ASSIS, Janaina Maria Oliveira de - jmoassis@gmail.com \\ Universidade Federal do Pernambuco / UFPE
}

SOUZA, Werônica Meira de Souza - weronicameira@gmail.com

Universidade Federal Rural do Pernambuco / UFRPE

$\mathrm{KOCH}$, Hagen - hagen.koch@pik-potsdam.de

Potsdam Institute for Climate Research / PIK - Potsdam

\author{
SOBRAL, Maria do Carmo Martins - mariadocarmo.sobral@gmail.com \\ Universidade Federal do Pernambuco / UFPE
}

\begin{abstract}
RESUMO: O objetivo deste trabalho é analisar as possíveis relações físicas entre os índices de extremos climáticos da precipitação, obtidos a partir do software Rclimdex desenvolvido pelo CLIVAR/NCDC/NOAA, e as anomalias da Temperatura da Superfície do Mar (TSM) nos oceanos Pacífico e Atlântico tropicais na região do Submédio da bacia hidrográfica do rio São Francisco. Para realização deste trabalho foram utilizados dados diários de precipitação pluviométrica de 36 postos pluviométricos no período de 1964 a 2016, fornecidos pela Agência Pernambucana de Águas e Clima (APAC), Instituto Nacional de Meteorologia (INMET) e Agência Nacional das Águas (ANA). Foram também utilizados dados de anomalias de Temperatura da Superfície do Mar (TSM) do Oceano Pacífico Equatorial nas regiões de Niño1+2, Niño3, Niño3.4 e Niño4, e Índices dos oceanos Atlântico Norte (TNAI) e Atlântico Sul (TSAI) no período de 1964 a 2016, oriundos da base de dados da National Oceanic and Atmospheric Administration (NOAA). O método usado foi o software RClimdex para o cálculo de 11 índices de extremos climáticos. Após o processamento do RClimdex foi realizada a correlação entre os 11 índices climáticos da precipitação com os índices oceânicos do Pacífico e Atlântico. Os resultados obtidos indicam que os índices de extremos climáticos apresentaram tendência negativa em praticamente todos os índices, com destaque para diminuição da precipitação total anual, situação que converge para a escassez hídrica na região. Constatou-se que as precipitações com tendências negativas são mais influenciadas pelas variações da Temperatura da Superfície do Mar (TSM) no oceano Pacífico em relação às variações no oceano Atlântico, evidenciando que o fenômeno El Niño influencia na redução das chuvas na bacia do Submédio São Francisco.
\end{abstract}

PALAVRAS-CHAVE: variabilidade climática, semiárido, bacia hidrográfica, El Niño, temperatura da superfície do mar.

INFLUENCE OF THE TROPICAL PACIFIC AND ATLANTIC OCEANS ON THE CLIMATE INDICATORS OF THE PRECIPITATION IN THE SÃO FRANCISCO SUBMEDIATE WATERSHED

ABSTRACT: The objective of this work is to analyze the possible physical relationships between precipitation climatic extremes indexes obtained from the Rclimdex software developed by CLIVAR / NCDC / NOAA and Sea Surface Temperature (SST) anomalies in the Pacific and Atlantic oceans in the sub-region of the São Francisco river basin. In order to carry out this work, daily rainfall data of 36 pluviometric stations from 1964 to 2016 were used, provided by the Pernambuco State of Water and Climate Agency (APAC), National Institute of Meteorology (INMET) and national water agency (ANA). Data from Sea Surface Temperature (SST) anomalies of the Equatorial Pacific Ocean in the regions of Niño1 + 2, Niño3, Niño3.4 and Niño4, and North Atlantic (TNAI) and South Atlantic 
(TSAI) period from 1964 to 2016, from the National Oceanic and Atmospheric Administration (NOAA) database. The method used was the RClimdex software for calculating 11 indexes of climatic extremes. After the RClimdex was processed the correlation between the 11 climatic indexes of the precipitation with the Pacific and Atlantic ocean indices was performed. The results indicate that the indexes of climatic extremes showed a negative trend in practically all indices, with a decrease in total annual rainfall, a situation that converges to the water scarcity in the region. It was observed that precipitations with negative trends are more influenced by the variations of the Sea Surface Temperature (SST) in the Pacific Ocean in relation to the variations in the Atlantic Ocean, evidencing that the El Niño phenomenon influences the reduction of rainfall in the Submedio São Francisco river basin.

KEYWORDS: climatic variability, semiarid, watershed, El Niño, sea surface temperature INFLUENCIA DE LOS OCÉANOS PACÍFICO Y ATLÁNTICO TROPICAL SOBRE LOS ÍNDICES CLIMÁTICOS DE LA PRECIPITACIÓN EN LA BACIA DEL SUBMEDIO SAN FRANCISCO

RESUMEN: El objetivo de este trabajo es analizar las posibles relaciones físicas entre los índices de extremos climáticos de la precipitación obtenidos a partir del software Rclimdex desarrollado por CLIVAR / NCDC / NOAA, y las anomalías de la Temperatura de la Superficie del Mar (TSM) en los océanos Pacífico y Atlántico tropicales en la región del Submedia de la cuenca del río San Francisco. Para la realización de este trabajo se utilizaron datos diarios de precipitación pluviométrica de 36 puestos pluviométricos en el período de 1964 a 2016, suministrados por la Agencia Pernambucana de Aguas y Clima (APAC), Instituto Nacional de Meteorología (INMET) y Agencia Nacional de las Aguas (ANA). Se utilizaron datos de anomalías de temperatura de la superficie del mar (TSM) del Océano Pacífico Ecuatorial en las regiones de Niño1 + 2, Niño3, Niño3.4 y Niño4, e Índices de los océanos Atlántico Norte (TNAI) y Atlántico Sur (TSAI) período de 1964 a 2016, provenientes de la base de datos de la National Oceanic and Atmospheric Administration (NOAA). El método utilizado fue el software RClimdex para el cálculo de 11 índices de extremos climáticos. Después del procesamiento del RClimdex se realizó la correlación entre los 11 índices climáticos de la precipitación con los índices oceánicos del Pacífico y del Atlántico. Los resultados obtenidos indican que los índices de extremos climáticos presentaron tendencia negativa en prácticamente todos los índices, con destaque para disminuir la precipitación total anual, situación que converge hacia la escasez hídrica en la región. Se constató que las precipitaciones con tendencias negativas son más influenciadas por las variaciones de la Temperatura de la Superficie del Mar (TSM) en el océano Pacífico en relación a las variaciones en el océano Atlántico, evidenciando que el fenómeno El Niño influye en la reducción de las Iluvias en la cuenca del Submedio São Francisco.

PALABRAS CLAVE: variabilidad climática, semiárido, cuenca hidrográfica, El Niño, temperatura de lasuperficiedel mar

\section{INFLUENCE DES OCÉANS TROPICAUX DU PACIFIQUE ET DE L'ATLANTIQUE SUR LES INDICATEURS CLIMATIQUES DE LA PRÉCIPITATION DANS LE BOL SUBMÉDIAIRE DE SÃO FRANCISCO}

RÉSUMÉ: L'objectif de ce travail est d'analyser les relations physiques possibles entre les indices des extrêmes climatiques de précipitation obtenus à partir du logiciel Rclimdex développé par CLIVAR / NCDC / NOAA et des anomalies de la température de surface de la mer (SST) dans les océans Pacifique et Atlantique. dans la sous-région du bassin du fleuve São Francisco. Afin de mener à bien ce travail, les données de pluviométrie journalière de 36 stations pluviométriques de 1964 à 2016 ont été utilisées, fournies par l'Agence de l'état de l'eau et du climat de Pernambouc (APAC), I'Institut national de météorologie (INMET) et Agência Nacional das Águas (ANA). Données provenant d'anomalies de la température de surface de la mer (SST) de l'océan Pacifique équatorial dans les régions de Niño1 + 2, Niño3, Niño3.4 et Niño4 et de l'Atlantique Nord (TNAI) et de I'Atlantique Sud (TSAI) période de 1964 à 2016, base de données de la NOAA (National Oceanic and Atmospheric Administration). La méthode utilisée a été le logiciel 
RClimdex pour le calcul de 11 indices d'extrémités climatiques. Après le traitement de RClimdex, la corrélation entre les 11 indices climatiques des précipitations et les indices océan Pacifique et Atlantique a été réalisée. Les résultats indiquent que les indices des extrêmes climatiques ont montré une tendance négative dans pratiquement tous les indices, avec une diminution des précipitations annuelles totales, une situation qui converge vers la pénurie d'eau dans la région. Il a été observé que les précipitations à tendance négative étaient davantage influencées par les variations de la température de surface de la mer (SST) dans l'océan Pacifique par rapport aux variations de l'océan Atlantique, ce qui montre que le phénomène El Niño a une influence sur la réduction des précipitations dans le bassin de Submédio São Francisco.

MOTS CLÉS: variabilité climatique, semi-aride, bassinversant, El Niño, température de lasurface de lamer

\section{INTRODUÇÃO}

A grande variabilidade do clima no Brasil controla as atividades socioeconômicas, sendo também responsável pela irregularidade na distribuição da precipitação, tanto em nível espacial como temporal, nas escalas sazonal e interanual. A região Nordeste do Brasil está entre as regiões mais vulneráveis aos impactos dessas variabilidades, devido suas características climáticas, assim como pelas condições socioeconômicas e políticas (Marengo, 2009). Além de ser uma região que enfrenta graves problemas relacionados à irregularidade das chuvas, e principalmente as secas severas e prolongadas, como também as chuvas intensas (Ferreira et al., 2017, Rodrigues et al., 2017).

A variabilidade da precipitação nessa área tem sido associada às anomalias de Temperatura de Superfície do Mar (TSM) do Pacífico equatorial que, na fase positiva (El Niño), favorece a redução da precipitação pluviométrica sobre a região Nordeste, enquanto na fase negativa (La Niña) contribui para a ocorrência de chuvas, algumas vezes acima da média histórica (Andreoli e Kayano, 2007).

O conhecimento em relação ao gradiente meridional de anomalias de TSM sobre o Atlântico Tropical, em conjunto com os episódios de El Niño/Oscilação do Sul (ENOS), modulam uma grande parte da variância interanual do clima sobre a América do Sul e Nordeste do Brasil (Aragão,1998). A combinação das circulações atmosféricas anômalas induzidas pela TSM sobre os oceanos Pacífico Equatorial e Atlântico Tropical afetam o posicionamento latitudinal da Zona de Convergência Intertropical (ZCIT) sobre o Atlântico (Gu e Adler, 2009), influenciando desta forma a distribuição da pluviometria sobre a região Nordeste do Brasil (Hastenrath, 1984; Nobre e Shukla, 1996).

O padrão de anomalias de TSM sobre o Atlântico Tropical geralmente associado a anomalias pluviométricas sobre o Nordeste apresenta anomalias de TSM com sinais opostos ao norte e ao sul do equador sobre o Atlântico Tropical (Hastenrath e Heller, 1977; Moura e Shukla, 1981). Nos anos que as TSMs sobre o Atlântico Tropical Sul estão mais elevadas que o Atlântico Norte, há formação de um gradiente meridional de TSM no sentido de norte para sul, com os ventos alísios de nordeste mais intensos que a média e os ventos de sudeste mais fracos, influenciando o posicionamento da ZCIT mais ao sul e totais pluviométricos acima da média sobre o Norte do Nordeste (Hastenrath e Heller, 1977).

Essas informações permitem que sejam elaboradas previsões sobre as precipitações na região Nordeste, contribuindo de forma efetiva para o 
planejamento socioeconômico da região (MOURA et. al., 2008). Desse modo, alguns modelos de previsão climática para o Nordeste, como o modelo regional ETA, já operacionais, vêm sendo utilizados por diversos organismos regionais, nacionais e internacionais, por meio dos quais é possível elaborar prognósticos sobre a qualidade da estação chuvosa, com antecedência de até seis meses para casos extremos de precipitação (MOURA et al., 2000).

De acordo com Chapman et al. (2013), os modelos climáticos têm melhorado ao longo das décadas em virtude das pesquisas e avanços tecnológicos, como o avanço da supercomputação, da modelagem e das infraestruturas de telecomunicação possibilitando resoluções cada vez melhores nos centros de pesquisa. Um exemplo disso pode ser observado nos diferentes modelos trabalhados nos relatórios do IPCC de 1995 e no de 2007.

Os modelos de clima utilizados no quinto relatório do IPCC (IPCC, 2013), garantem a sensibilidade dos mesmos usados anteriormente, no entanto são atualmente mais realistas, sobretudo em relação aos eventos de precipitação e aumento dos gases de efeito estufa. A representação mais realista das variáveis meteorológicas está associada a um aumento da resolução e parametrização física dos modelos, embora isto não apresente a mesma configuração em relação aos modelos globais e regionais (CHAPMAN, STAINFORTH e WATKINS, 2013).

Significativas mudanças climáticas globais foram observadas ao longo do século passado. Como foi relatado no documento síntese de construção do $5^{\circ}$ Relatório de Avaliação (AR5) do Painel Intergovernamental de Mudanças Climáticas (IPCC, 2013). O aquecimento do sistema climático é inequívoco e muitas das mudanças observadas foram sem precedentes e sobre diferentes escalas temporais (STOCKER et. al., 2013). A síntese do relatório também indicou que eventos extremos de clima estão relacionados ao aumento da frequência, e duração da precipitação (SELEY et. al., 2014; YILMAZ et. al., 2014). De acordo com Grassi et. al. (2013), Chang et. al. (2013) e Zhang et. al. (2014), os eventos climáticos extremos estão diretamente relacionados com mudanças climáticas, que tem induzido anomalias hidrológicas e térmicas, refletindo diretamente no modo de vida de toda população e alterando as relações existentes.

Para analisar as mudanças climáticas sobre o Nordeste do Brasil, é importante identificar os processos que influenciam o padrão das distribuições pluviométricas, tanto espacial quanto temporal. Um fator relevante a ser destacado nesse contexto é a irregularidade na distribuição da precipitação, associado a sua alta variabilidade interanual na região tropical, com anos secos e outros chuvosos. Diversos fatores podem contribuir para explicar a alta variabilidade da precipitação sobre o Nordeste do Brasil, dentre os quais, podem ser citados, a flutuação nos valores de Temperatura da Superfície do Mar (TSM) do Oceano Pacífico Tropical e do Atlântico. No geral, os valores das anomalias da TSM, do Pacífico Tropical e Atlântico, estão associados a mudanças no padrão da circulação geral da atmosfera e consequentes variações na precipitação do Nordeste do Brasil. De acordo com Menezes et al. (2008), é interessante correlacionar os índices de extremos climáticos com as anomalias de TSM, visto que tais anomalias nos oceanos Pacífico e Atlântico Tropicais são a principal variável física influenciadora das condições da variabilidade climática no Nordeste do Brasil. 
No oceano Pacífico, o fenômeno climático El Niño causa variações e flutuações periódicas em escala interanual na América do Sul, sobretudo na Amazônia e região Nordeste do Brasil (KOUSKY, KAYANO e CAVALCANTI, 1984; KAYANO, RAO e MOURA, 1988; ARAÚJO, 2011). A variabilidade da precipitação nessa área tem sido associada às anomalias da Temperatura de Superfície do Mar (TSM) do Pacífico equatorial que, na fase positiva (El Niño), favorece a redução da precipitação pluviométrica sobre a região Nordeste, enquanto na fase negativa (La Niña) contribui para a ocorrência de chuvas, algumas vezes acima da média histórica (ANDREOLI e KAYANO, 2007).

Rodrigues et al. (2017) ressalta que os eventos de El Niño, independente da sua magnitude, não explicam sozinhos os anos secos, assim como os eventos de La Niña não estão associados, necessariamente, a anos chuvosos no semiárido nordestino. A interação desses fenômenos com os sistemas meteorológicos e com as condições favoráveis do Atlântico Tropical sul (TSM mais elevada que o Atlântico Tropical Norte) é que são determinantes no regime de chuvas do semiárido.

Este trabalho teve como objetivo analisar as possíveis relações físicas entre os índices de extremos climáticos na região do Submédio da bacia hidrográfica do rio São Francisco e as anomalias da Temperatura da Superfície do Mar (TSM) nos oceanos Pacífico e Atlântico tropicais. A motivação para realizar este estudo parte de observações relacionadas aos prolongados períodos de estiagens que repercute na quebra de safras agrícolas (MORANDO et. Al, 2014, ASSAD, 2004), déficit hídrico (MARENGO 2014), crises de abastecimento urbano e rural (SOBRAL, 2017) e problemas na geração de energia hidroelétrica (Koch et al., 2018).

\section{MATERIAL E MÉTODOS}

\section{1 ÍNDICES DE EXTREMOS CLIMÁTICOS}

Os dados diários de precipitação foram obtidos de 36 estações pluviométricas distribuídas no trecho Submédio da bacia hidrográfica do rio São Francisco, conforme Figura 1, compreendendo os estados de Pernambuco e Bahia, no período de 1964 a 2016. 


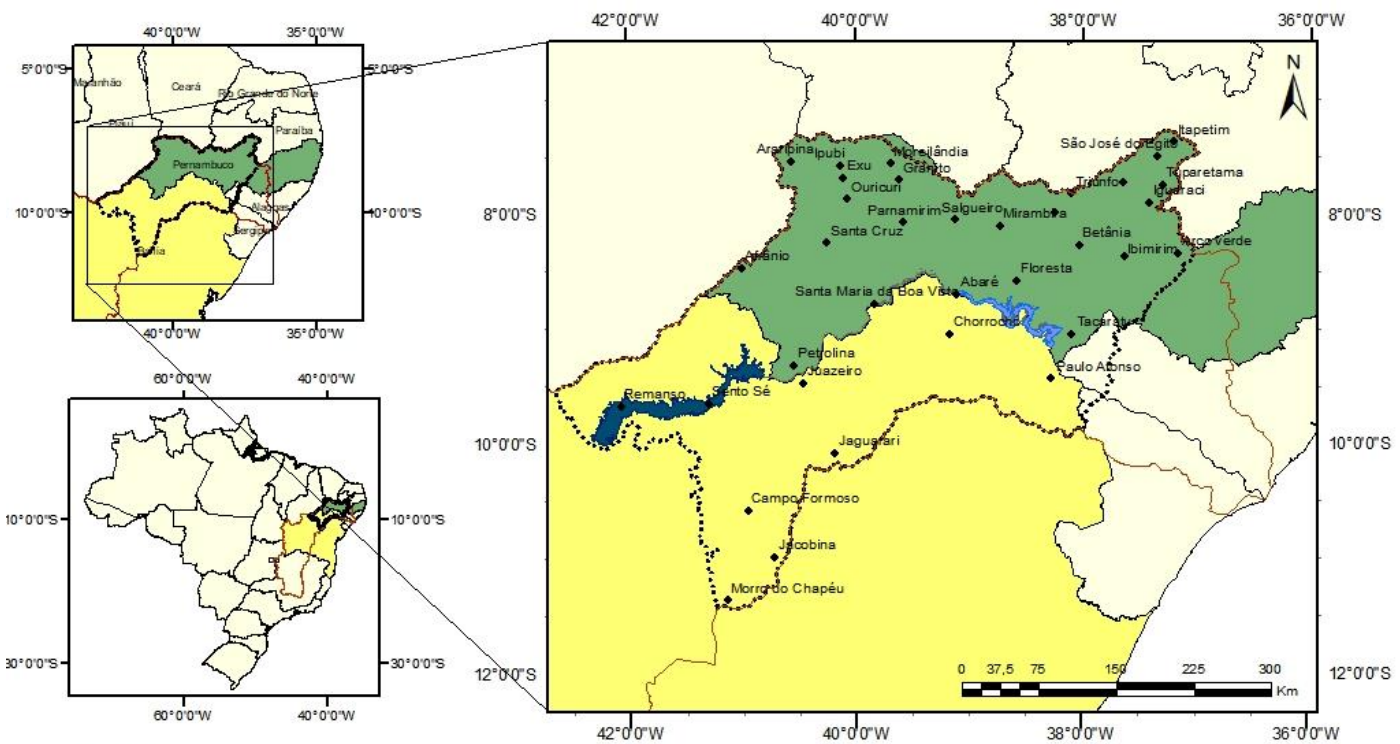

Legenda

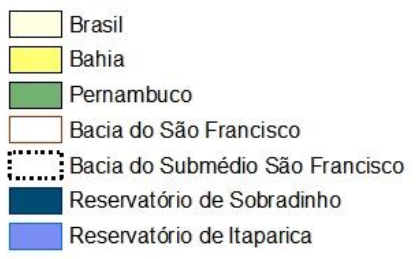

Escala: 1:4.000.000

Sistema de Projeção GCS WGS 84 - Fuso 24 Sul Fontes de Dados Utilizados:

IBGE - Portal Brasileiro de Dados Abertos e ANA - Agência Nacional das Águas

- Postos pluviométricos

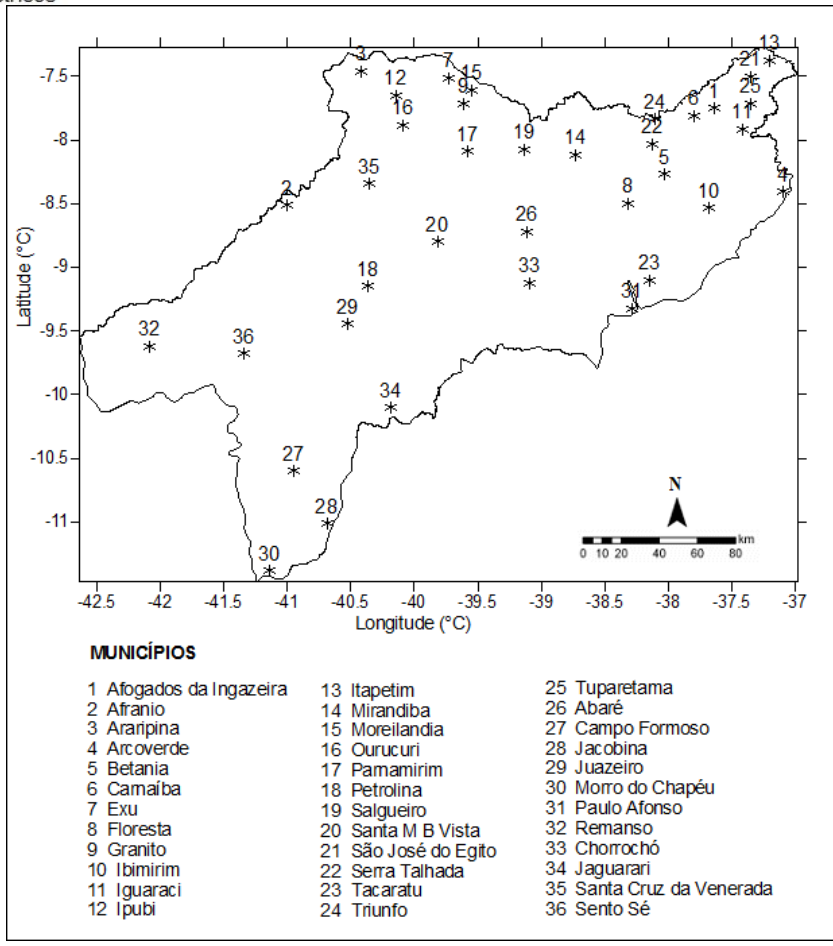

Figura 1- Localização e distribuição espacial dos postos pluviométricos no Submédio do rio São Francisco. Fonte: Adaptado de Sobral et al, 2018 
Os dados de precipitação foram obtidos na Agência Pernambucana de Águas e Clima (APAC), através do banco de dados online, disponível no endereço http://www.apac.pe.gov.br/meteorologia/monitoramento-pluvio.php e na Agência Nacional de Águas (ANA), em seu sistema de informações hidrológicas - HIDROWEB, através do site http://hidroweb.ana.gov.br/.

Os índices de extremos climáticos foram obtidos a partir do software RClimdex 3.2.1, desenvolvido por uma equipe de especialistas do Climate and Ocean - Variability, Predictability, and Change (CLIVAR) do National Climate Data Centre (NCDC) da National Oceanic and Atmospheric Administration (NOAA) sobre os índices de detecção de Mudanças Climáticas (Zhang, X.; Yang, F., 2004). O software foi desenvolvido para linguagem computacional $R$, disponível no site http://cccma.seos.uvic.ca/ETCCDMI. A primeira versão foi elaborada por Byron Gleason (2001) no Centro Nacional de Dados Climáticos (NCDC) da NOAA, e tem sido usado em workshops do CLIVAR.

O RClimdex 3.2.1 calcula todos os 27 índices básicos (11 para precipitação e 16 para temperatura) recomendados pelo Expert Team on Climate Change Detection Monitoring and Indices (ETCCDMI) e fornece, para cada índice calculado, informações estatísticas, tais como tendência linear calculada pelo método de mínimos quadrados, nível de significância estatística da tendência (valor $p$ ), coeficiente de determinação $\left(R^{2}\right)$ e erro padrão de estimativa, além dos gráficos das séries anuais. Neste trabalho foram utilizados apenas os índices dependentes da precipitação (Zhang, X.; Yang, F., 2004), conforme Tabela 1.

Tabela 1 - Índices de extremos climáticos dependentes da precipitação com definições e unidades

\begin{tabular}{|c|c|c|c|}
\hline ÍNDICE & NOME DO INDICADOR & PARÂMETROS & UNIDADE \\
\hline PRCPTOT & $\begin{array}{c}\text { Precipitação total anual nos } \\
\text { dias úmidos }\end{array}$ & $\begin{array}{l}\text { Precipitação total anual nos dias } \\
\text { úmidos (RR* } \geq 1 \mathrm{~mm})\end{array}$ & $\mathrm{mm}$ \\
\hline CDD & Dias consecutivos secos & $\begin{array}{l}\text { Número máximo de dias } \\
\text { consecutivos com } R^{*}<1 \mathrm{~mm}\end{array}$ & dias \\
\hline CWD & Dias úmidos consecutivos & $\begin{array}{l}\text { Número máximo de dias } \\
\text { consecutivos } R R \geq 1 \mathrm{~mm}\end{array}$ & dias \\
\hline R10mm & $\begin{array}{l}\text { Número de dias com } \\
\text { precipitação acima de } 10 \mathrm{~mm}\end{array}$ & $\begin{array}{l}\text { Número de dias por ano em que } \\
\text { a precipitação foi } \geq 10 \mathrm{~mm}\end{array}$ & dias \\
\hline R20mm & $\begin{array}{l}\text { Número de dias com } \\
\text { precipitação acima de } 20 \mathrm{~mm}\end{array}$ & $\begin{array}{l}\text { Número de dias por ano em que } \\
\text { a precipitação foi } \geq 20 \mathrm{~mm}\end{array}$ & dias \\
\hline R50mm & $\begin{array}{l}\text { Número de dias com } \\
\text { precipitação acima de } 50 \mathrm{~mm}\end{array}$ & $\begin{array}{l}\text { Número de dias por ano em que } \\
\text { a precipitação foi } \geq 50 \mathrm{~mm}\end{array}$ & dias \\
\hline SDII & $\begin{array}{l}\text { Índice simples de intensidade } \\
\text { diária }\end{array}$ & $\begin{array}{l}\text { Precipitação anual total dividida } \\
\text { para o número de dias úmidos } \\
\text { (definidos por PRCPTOT } \geq 1 \mathrm{~mm} \text { ) }\end{array}$ & $\mathrm{mm} / \mathrm{dia}$ \\
\hline Rx1day & $\begin{array}{l}\text { Quantidade máxima de } \\
\text { precipitação em } 1 \text { dia }\end{array}$ & $\begin{array}{c}\text { Máximo mensal de precipitação } \\
\text { em } 1 \text { dia }\end{array}$ & $\mathrm{mm}$ \\
\hline Rx5day & $\begin{array}{l}\text { Quantidade máxima de } \\
\text { precipitação em } 5 \text { dias } \\
\text { consecutivos }\end{array}$ & $\begin{array}{l}\text { Máximo mensal de precipitação } \\
\text { em } 5 \text { dias consecutivos }\end{array}$ & $\mathrm{mm}$ \\
\hline R95p & Dias muito úmidos & $\begin{array}{l}\text { Precipitação total anual em que } \\
\text { RR }>95 \text { percentil }\end{array}$ & $\mathrm{mm}$ \\
\hline R99p & Dias extremamente úmidos & $\begin{array}{l}\text { Precipitação total anual em que } \\
\text { RR }>99 \text { percentil }\end{array}$ & $\mathrm{mm}$ \\
\hline
\end{tabular}




\section{2 ÍNDICES OCEÂNICOS NO PACÍFICO E NO ATLÂNTICO}

Após o processamento dos dados a partir do RClimdex, foi realizada a correlação entre os índices climáticos observados nos 36 postos pluviométricos com os índices oceânicos, visando identificar as possíveis relações físicas entre essas variáveis no Submédio São Francisco.

Foram utilizadas as anomalias dos índices oceânicos medidos no Pacífico

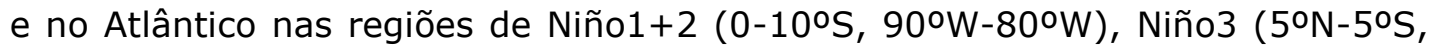

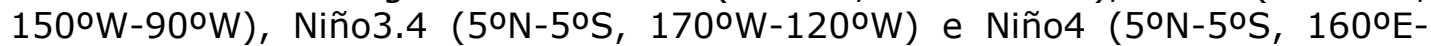
$\left.150^{\circ} \mathrm{W}\right) \quad$ monitoradas pela NOAA (https://www.esrl.noaa.gov/psd/data/climateindices/list);o Índice Mensal do Atlântico Tropical Norte (TNAI), que é a anomalia de TSM na área compreendida entre $5^{\circ} \mathrm{N}-23,5^{\circ} \mathrm{N}$ e $15^{\circ} \mathrm{W}-57,5^{\circ} \mathrm{W}$, e o Índice Mensal do Atlântico Tropical Sul (TSAI), que é a anomalia de TSM na área compreendida entre $0-20^{\circ} \mathrm{S}$ e $10^{\circ} \mathrm{E}-$ 30W (Enfield et al., 1999), também monitoradas pela NOAA . Ressalta-se que as áreas do TNAI e TSAI correspondem à região associada ao gradiente meridional do Atlântico Tropical (Moura e Shukla, 1981; Servain, 1991).

Os índices utilizados e suas regiões oceânicas estão descritos e apresentados na Figura 2, a saber:

a) Niño $\mathbf{1 + 2}$ - na parte oeste do oceano Pacífico equatorial próxima à costa do Peru na América do Sul. b) Niño 3 - entre as regiões Niño $\mathbf{1 + 2}$ e Niño $\mathbf{3 . 4}$ no oceano Pacífico equatorial. c) Niño 3.4 - na porção central do oceano Pacífico equatorial entre a América do Sul e o continente australiano. d) Niño 4 - na parte oeste do oceano Pacífico equatorial próximo ao continente australiano. e) Índice de Oscilação Sul (IOS) - entre as ilhas australianas de Tahiti e Darwin no oceano Pacífico equatorial. f) Índice Oceânico Niño (ION) - na região Niño 3.4 do oceano Pacífico equatorial. g) Índice Atlântico Tropical Norte (TNAI) - na porção norte do oceano Atlântico ou acima da linha do equador. h) Índice Atlântico Tropical Sul (TSAI) - na porção sul do oceano Atlântico ou abaixo da linha do equador.

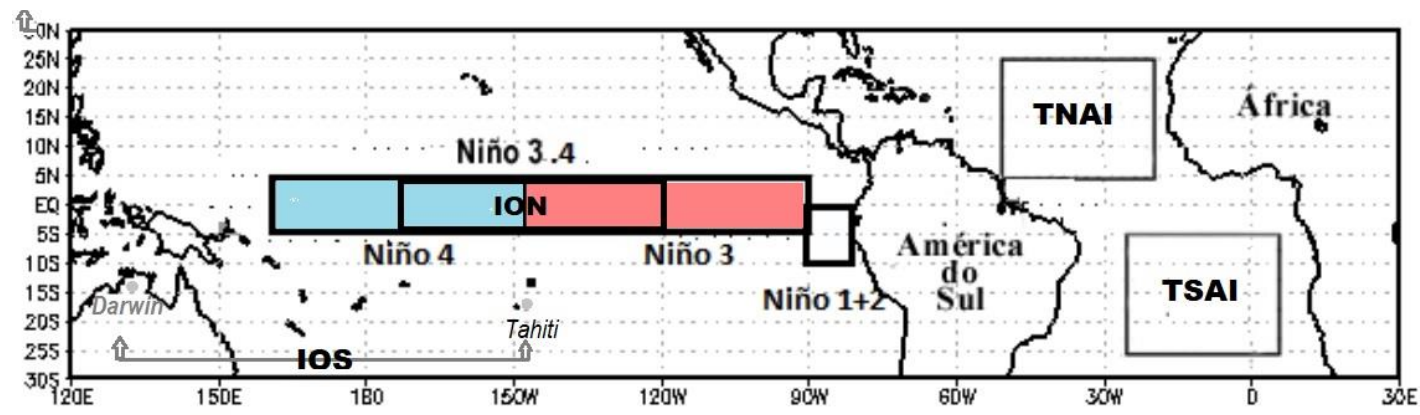

Figura 2- Identificação das regiões de Niño 1+2, Niño3, Niño 3.4 e Niño4 no oceano Pacífico Equatorial, e das regiões do TNAI e TSAI no oceano Atlântico Tropical, com destaque para os índices em negrito. Fonte: Adaptada da NOAA, 2018 


\subsection{CORRELAÇÃO LINEAR}

Para o cálculo das correlações lineares entre os índices de extremos climáticos e os índices de anomalias de TSM nos oceanos Pacífico e Atlântico, foi utilizado o Método da correlação de Pearson (MAGALHÃES e LIMA, 2010), também conhecido como Coeficiente de Correlação do Momento Produto conforme equação 1 :

$$
r=\frac{\sum_{i=1}^{n}\left(x_{i}-\bar{x}\right)\left(y_{i}-\bar{y}\right)}{\sqrt{\left[\sum_{i=1}^{n}\left(x_{i}-\bar{x}\right)^{2}\right]}\left[\sum_{i=1}^{n}\left(y_{i}-\bar{y}\right)^{2}\right]}
$$

Em que:

n é o número de observações da amostra;

$X$ é a média aritmética de $X$;

Y é a média aritmética de $\mathrm{Y}$.

A significância do coeficiente de correlação será avaliada a partir do teste de hipótese t-Student (MAGALHÃES e LIMA, 2010), para os níveis de significância de $1 \%, 5 \%$ e $10 \%$ e graus de liberdade de $(n-2)$. As rejeições às hipóteses nulas ho irão identificar a existência de correlação linear entre as combinações realizadas. Para testar a hipótese de que o coeficiente de correlação linear é igual a zero, tem-se que: $H_{-} 0: \rho=0$ e $H_{-} 1: \rho \neq 0$, conforme a equação 2:

Em que:

$$
t=\frac{\widehat{\rho} \sqrt{n-2}}{\sqrt{1-\widehat{\rho^{2}}}} \sim t_{n-2}
$$

t_0 é a estatística do teste;

n é o tamanho da amostra;

$r$ é a estimativa do coeficiente de correlação linear.

Sob o pressuposto da hipótese nula $H_{-} 0: \rho=0$. A hipótese nula é rejeitada se (MAGALHÃES e LIMA, 2010):

$$
\left|t_{0}\right|>t \alpha / 2(n-2)
$$

Após realizada a correlação de Pearson entre os índices climáticos observados nos 36 postos pluviométricos com os índices oceânicos do Pacífico e Atlântico, foi elaborada uma tabela com a média dos valores observados dos índices climáticos e dos índices oceânicos, e posteriormente mapas com os índices que apresentaram significancia estatística, visando identificar as possíveis relações físicas entre os índices climáticos e os índices oceânicos na região do Submédio da bacia hidrográfica do rio São Francisco.

\section{RESULTADOS E DISCUSSÃO}

Os resultados de correlação entre os índices de extremos climáticos da precipitação e os índices oceânicos, apresentado na Tabela 2, evidenciaram que as precipitações com sinal negativo são bem mais influenciadas pelas variações 
da TSM no oceano Pacífico em relação às variações no oceano Atlântico, indicando que as temperaturas elevadas no oceano Pacífico podem influenciar na diminuição da precipitação na bacia do Submédio São Francisco.

A Figura 3a apresenta a distribuição da média da precipitação total anual durante o período analisado (1964 - 2016), onde se observa que em toda parte central do Submédio, a precipitação se concentra entre $300 \mathrm{~mm}$ e $600 \mathrm{~mm}$, sendo mais escassa ao sul da sub-bacia, mais próximo ao rio São Francisco. A Figura 3b apresenta a evolução temporal da distribuição da precipitação total anual, onde se verifica a grande variabilidade interanual das chuvas e uma diminuição gradual das chuvas ao longo dos últimos 52 anos. Essas análises são importantes, uma vez que se tem por objetivo central analisar as relações entre os índices de extremos climáticos na região do Submédio e as anomalias da Temperatura da Superfície do Mar (TSM) nos oceanos Pacífico e Atlântico tropicais.

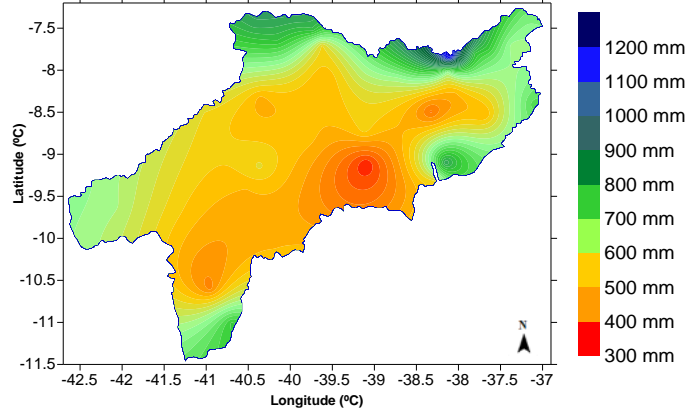

(A)

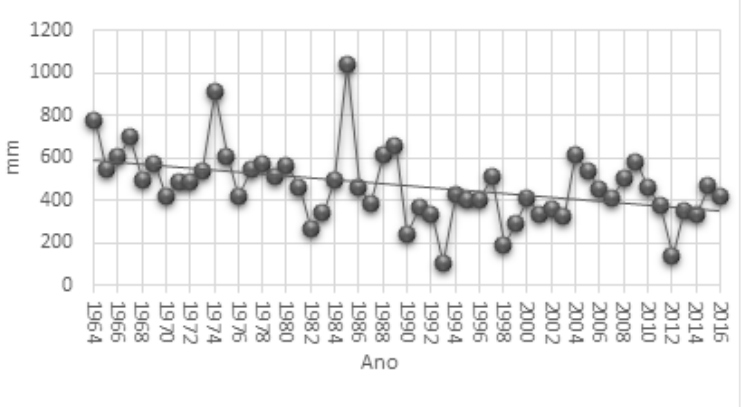

(B)

Figura 3 - Distribuição da precipitação total anual no Submédio São Francisco (1964 2016)

Os índices oceânicos Niño 1+2, Niño3 e Niño 3.4, Niño 4 e ION, medidos no Pacífico, apresentam maior correlação linear negativa, com significância estatística, com os índices climáticos de precipitação. Já o índice IOS, também medido no Pacífico, indica sinais contrários, com predominância de correlação linear positiva. Na anomalia de TSM do oceano Atlântico, TNA, do mesmo modo das regiões do Pacífico, obteve predominância de anomalias negativas, já a região TSA, do Atlântico, apresenta grande variabilidade das anomalias, oscilando entre correlações positivas e negativas (Tabela 2). 
Tabela 2 - Correlações entre os índices de extremos climáticos e os índices oceânicos do Pacífico e Atlântico

Oceano Pacífico Equatorial

Oceano Atlântico

\begin{tabular}{lcccccccc}
\cline { 2 - 7 } \multicolumn{1}{c}{ Índices } & Niño1+2 & Niño3 & Niño3.4 & Nino4 & IOS & ION & TNA & TSA \\
\hline PRECPTOT & $-0,42^{* *}$ & $-0,43^{* *}$ & $-0,34^{*}$ & $-0,31^{*}$ & $0,35^{* *}$ & $-0,27$ & $-0,24$ & 0,04 \\
CDD & 0,23 & 0,20 & 0,15 & 0,10 & $-0,29^{*}$ & 0,12 & $-0,08$ & $-0,20$ \\
CWD & $-0,15$ & $-0,15$ & $-0,13$ & $-0,06$ & 0,21 & $-0,15$ & 0,14 & 0,13 \\
R10 & $-0,42^{* *}$ & $-0,43^{* *}$ & $-0,34^{*}$ & $-0,32^{*}$ & $0,34^{*}$ & $-0,26$ & $-0,32^{*}$ & 0,01 \\
R20 & $-0,39^{* *}$ & $-0,40^{* *}$ & $-0,32^{*}$ & $-0,30^{*}$ & $0,31^{*}$ & $-0,23$ & $-0,29^{*}$ & $-0,02$ \\
R50 & $-0,21$ & $-0,22$ & $-0,15$ & $-0,13$ & 0,17 & $-0,12$ & $-0,20$ & 0,01 \\
R95p & $-0,34^{*}$ & $-0,36^{* *}$ & $-0,29^{*}$ & $-0,24$ & $0,31^{*}$ & $-0,24$ & $-0,14$ & 0,02 \\
R99p & $-0,30^{*}$ & $-0,31^{*}$ & $-0,24$ & $-0,17$ & 0,25 & $-0,21$ & $-0,02$ & $-0,00$ \\
RX1day & $-0,37^{* *}$ & $-0,32^{*}$ & $-0,21$ & $-0,12$ & 0,21 & $-0,16$ & $-0,08$ & $-0,03$ \\
RX5day & $-0,26$ & $-0,24$ & $-0,16$ & $-0,10$ & 0,16 & $-0,12$ & $-0,03$ & $-0,13$ \\
SDII & $-0,12$ & $-0,13$ & $-0,07$ & $-0,14$ & $-0,05$ & 0,04 & $-0,41^{* *}$ & $-0,32^{*}$
\end{tabular}

** A correlação é significativa no nível $\mathrm{p}=0,01$. *A correlação é significativa no nível $\mathrm{p}=0,05$

Ao analisar as anomalias de TSM nas regiões de Niño $1+2$ e Niño 3 observam-se as maiores correlações negativas, com significância estatística, com os índices climáticos PRCPTOT, R10mm, R20mm, R95p, R99p e Rx1day, indicando que quando a TSM aumenta há uma redução na precipitação total anual, e consequentemente tendência negativa desses índices. Ao analisar as anomalias de TSM nas regiões de Niño $1+2$ e Niño 3 observam-se as maiores correlações negativas, com significância estatística, com os índices climáticos PRCPTOT, R10mm, R20mm, R95p, R99p e Rx1day, indicando que quando a TSM aumenta há uma redução na precipitação total anual, e consequentemente tendência negativa desses índices. De forma geral, durante os eventos de El Niño verifica-se na América do Sul subtropical um aumento da precipitação, principalemente, sobre a região sul do Brasil, que está associado a uma situação de bloqueio atmosférico e intensificação do Jato Subtropical (Diaz et al, 1998; Ropelewski e Halpert, 1987). Por outro lado, na região Nordeste do Brasil há secas devido o deslocamento da célula de Walker (Ropelewski e Halpert, 1987; Kousky e Kayano, 1994; Grimm, 2003).

No norte e nordeste da América do Sul, o Atlântico Tropical pode agir como modulador da precipitação mesmo em anos de eventos extremos de ENOS (Uvo et al, 1998; Coelho et al., 2002; Souza et al, 2004). Estudo realizado por Ambrizzi et al. (2004) mostrando a influência dos eventos extremos de ENOS sobre as células regionais de Walker e Hadley e seus respectivos impactos sobre a precipitação sazonal da América do Sul, constataram que nem todos os eventos El Niño e La Niña produzem impactos associados à atuação conjunta do Pacífico Equatorial e do Atlântico Tropical na modulação das células de circulação regionais e, consequentemente, da precipitação nessa região. 
Segundo Sant'Anna Neto (2005), em anos de El Niño há uma redução dos movimentos convectivos nas regiões Norte e Nordeste do Brasil, gerando um bloqueio ao avanço das Frentes Frias em direção a essas regiões, que ficam semi-estacionárias no Sul do Brasil, aumentando, assim, os níveis de chuva, especialmente nos estados da região Sul e diminuição no Norte e Nordeste brasileiro. Na bacia do Submédio São Francisco as instabilidades das Frentes Frias são um dos principais sistemas meteorológicos responsáveis pela convecção na região, e em anos de El Niño podem afetar a quadra chuvosa principalmente nos meses de dezembro e janeiro, nestes meses há uma redução das chuvas.

As regiões (Niño $1+2$ e Niño 3) apresentam correlação positiva apenas para o índice climático CDD, que representa os dias consecutivos secos, embora sem significância estatística. O fato dessas regiões do Pacífico terem correlação positiva com o índice CDD indica que, quando a TSM aumenta, observa-se uma diminuição na precipitação do Submédio São Francisco, levando a um aumento do número de dias consecutivos sem chuva.

Resultados semelhantes foram encontrados por Ramos et al. (2011), em estudo para a Amazônia, onde concluiu que através das correlações entre os índices de extremos climáticos dependentes da precipitação diária para a região de Manaus e as anomalias de TSM nos Oceanos Pacífico e Atlântico, houve um aumento das anomalias positivas de TSM nas regiões de Niño levando a um aumento dos dias consecutivos secos e, diminuição dos eventos extremos de chuva e da precipitação total sobre a Bacia Amazônica.

De acordo com Andreoli et al. (2004) as secas severas no Nordeste têm sido relacionadas à ocorrência do fenômeno do El Niño. Em anos de El Niño, a circulação de Walker é deslocada para leste, tal que seu ramo ascendente localiza-se sobre o oceano Pacífico central e leste onde a convecção é intensificada, e seu ramo descendente localiza-se sobre o Nordeste do Brasil e Atlântico Tropical adjacente, onde a convecção é inibida. Convém lembrar que as células de Walker são células de circulação zonal, definidas na região equatorial, que se organizam entre os continentes e os oceanos, onde ocorre ascensão sobre os continentes (mais quentes) e subsidência sobre os oceanos (mais frios), de modo particular nas regiões orientais do Pacífico e do Atlântico (ALVES et al., 2007).

Seguindo o mesmo parâmetro, Santos et al. (2012), em estudo para a região Norte do Brasil, concluiu que, através das correlações entre os índices de extremos climáticos e as anomalias de TSM foi constatado que o aumento das anomalias positivas de TSM nessas regiões leva a um aumento dos dias consecutivos secos e a uma diminuição da precipitação total.

A distribuição espacial das correlações das regiões do Niño $1+2$ e Niño3 com os índices climáticos (R10mm, R20mm, R95p, R99p e Rx1day), que apresentaram significância estatística $(p=0,01$ e $p=0,05)$, estão representadas através das Figuras 4 e 5 , respectivamente. 


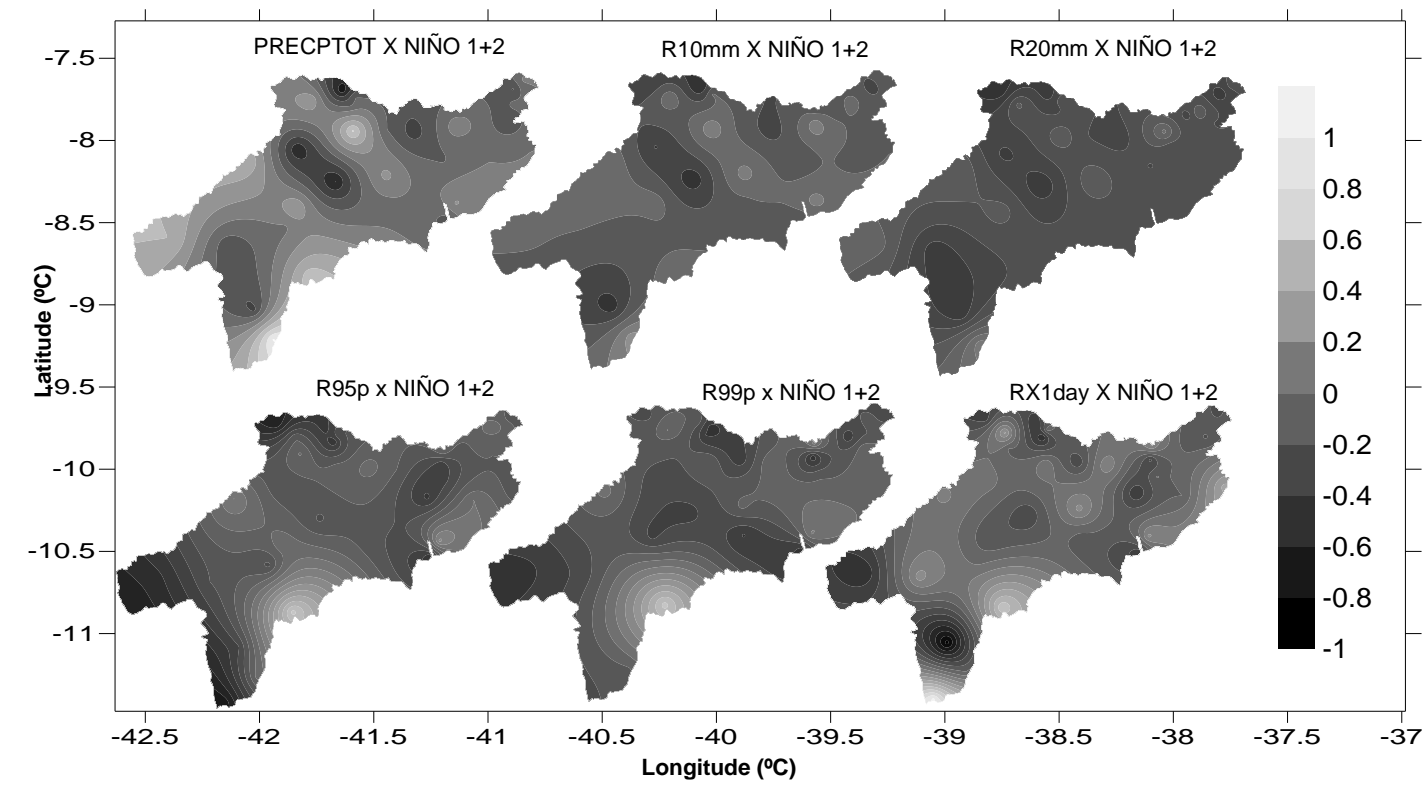

Figura 4 - Correlações entre os índices climáticos PRCPTOT, R10mm, R20mm, R95p, R99p e RX1day e região do oceânico Pacífico Niño $1+2$

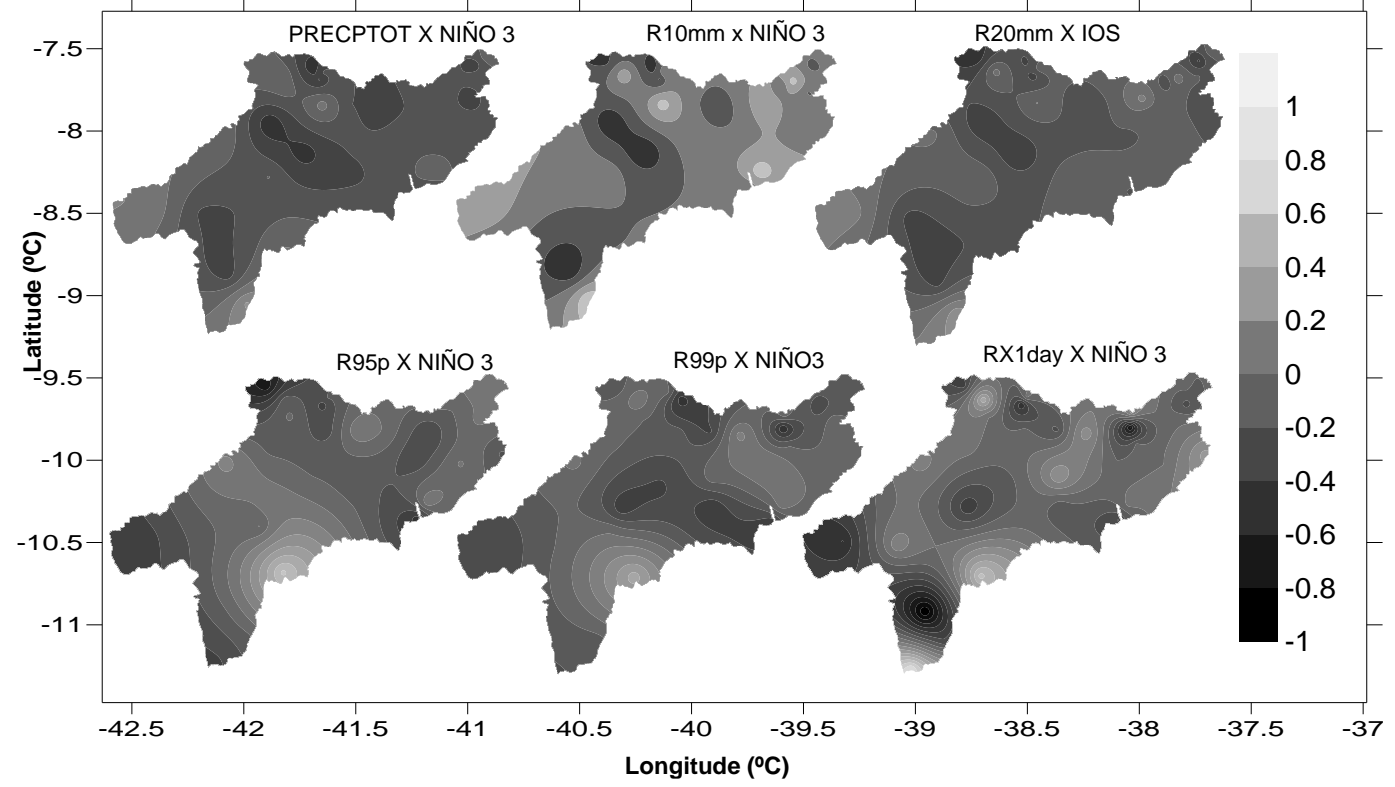

Figura 5 - Correlações entre os índices climáticos PRCPTOT, R10mm, R20mm, R95p, R99p e RX1day e região do oceânico Pacífico Niño 3

As maiores correlações negativas entre Niño $1+2$ e Niño 3 com a precipitação total anual (PRCPTOT) e os dias com chuva superior à $10 \mathrm{~mm}$ (R10mm) e $20 \mathrm{~mm}$ (R20mm) se concentraram na parte Centro-Oeste da bacia, região do Araripe, em Pernambuco e no Sul do Submédio, abrangendo a região do Centro Norte baiano, porém em maior intensidade na região Niño $1+2$, evidenciando que nessas áreas realmente sofrem um impacto consistente 
durante eventos provocados pelo fenômeno El Niño no sentido de diminuição da precipitação. A redução das chuvas pode estar associada ao bloqueio do avanço das Frentes Frias em direção ao Nordeste do Brasil, que atuam principalmente nos meses de dezembro e janeiro na referida bacia hidrográfica (Moura et al., 2000; Climanálise, 1996; Alves et al., 1993); ficando semi-estacionárias no Sul do país em anos de El Niño (Kousky e Cavalcanti, 1984), Satyamurty et al.,1998). DIAZ et al (1998) estudando anos de ENOS observaram que existe uma relação entre anos El Niño e alterações no regime de precipitações no Rio Grande do Sul e Uruguai, com maior incidência de chuvas no final da primavera e início do verão na região sul e do Brasil e secas no Nordeste brasileiro.

O índice R95p apresentou correlação negativa em quase toda a extensão do Submédio, com exceção da parte Sul da bacia e região do Araripe (Pernambuco). Para esse índice climático observa-se também uma maior influência da região de Niño $1+2$, que mostra correlações mais negativas do que a região Niño3, revelando diminuição dos dias úmidos com aumento das anomalias de TSM.

Em contrapartida, o índice R99p apresentou correlações positivas com os índices oceânicos Niño $1+2$ e Niño 3 em diferentes partes da bacia, apresentando a maior correlação, igualmente ao R95p, na parte Sul do Submédio, no estado da Bahia. A correlação existente entre essas regiões do oceano Pacífico com a quantidade máxima de precipitação em um dia (Rx1day) seguiu o mesmo parâmetro dos índices anteriores, apresentando a maior correlação na parte mais ao Sul da área estudada, que chegou ao nível máximo. Logo, observa-se uma influência das anomalias de TSM nas regiões do Pacífico Niño $1+2$ e Niño3 sobre os extremos de chuvas diárias registradas na parte Sul do Submédio São Francisco, revelando que apesar do aumento da TSM influenciar na redução da precipitação total anual, podem ocorrer eventos extremos de precipitação registrados em um dia, os quais estão associados aos fenômenos meteorológicos de tempo.

Pode-se verificar, ainda na Tabela 1, que os índices oceânicos nas regiões Niño 3.4 e Niño 4 apresentam correlações negativas com todos os índices climáticos, com exceção do índice de dias secos consecutivos, igualmente às regiões Niño $1+2$ e Niño 3, embora sem significância estatística, indicando possivelmente que quando a TSM aumenta nessas regiões, ocorre um aumento do número de dias sem chuva e consequente diminuição da precipitação. Resultados similares foram encontrados por Araújo e Brito (2007) em estudo realizado na Paraíba e Rio Grande do Norte e por Salgueiro et al. (2016) na Sub-bacia 39 do Nordeste brasileiro.

A distribuição espacial da correlação negativa na região do Niño $3.4 \mathrm{com}$ a precipitação (PRCPTOT) é semelhante aos padrões encontrados nas regiões Niño 1+2 e Niño 3, porém apresentando maior influência na diminuição das chuvas no setor central da bacia, abrangendo a região do baixo Pajeú (Pernambuco), mais próxima ao rio São Francisco. Em relação aos dias com chuvas moderadas (R10), observa-se uma maior correlação negativa na parte central, em direção à parte sul do Submédio. Os demais índices com significância estatística mostraram as maiores correlações negativas na região de Araripina (Pernambuco). Vale salientar que a região do Pacífico 3.4 corresponde à área de influência dos episódios de El Niño e La Niña, que são 
observados na porção central e equatorial do oceano Pacífico. A Figura 6 apresenta a correlação espacial entre a região Niño 3.4 e os índices climáticos.

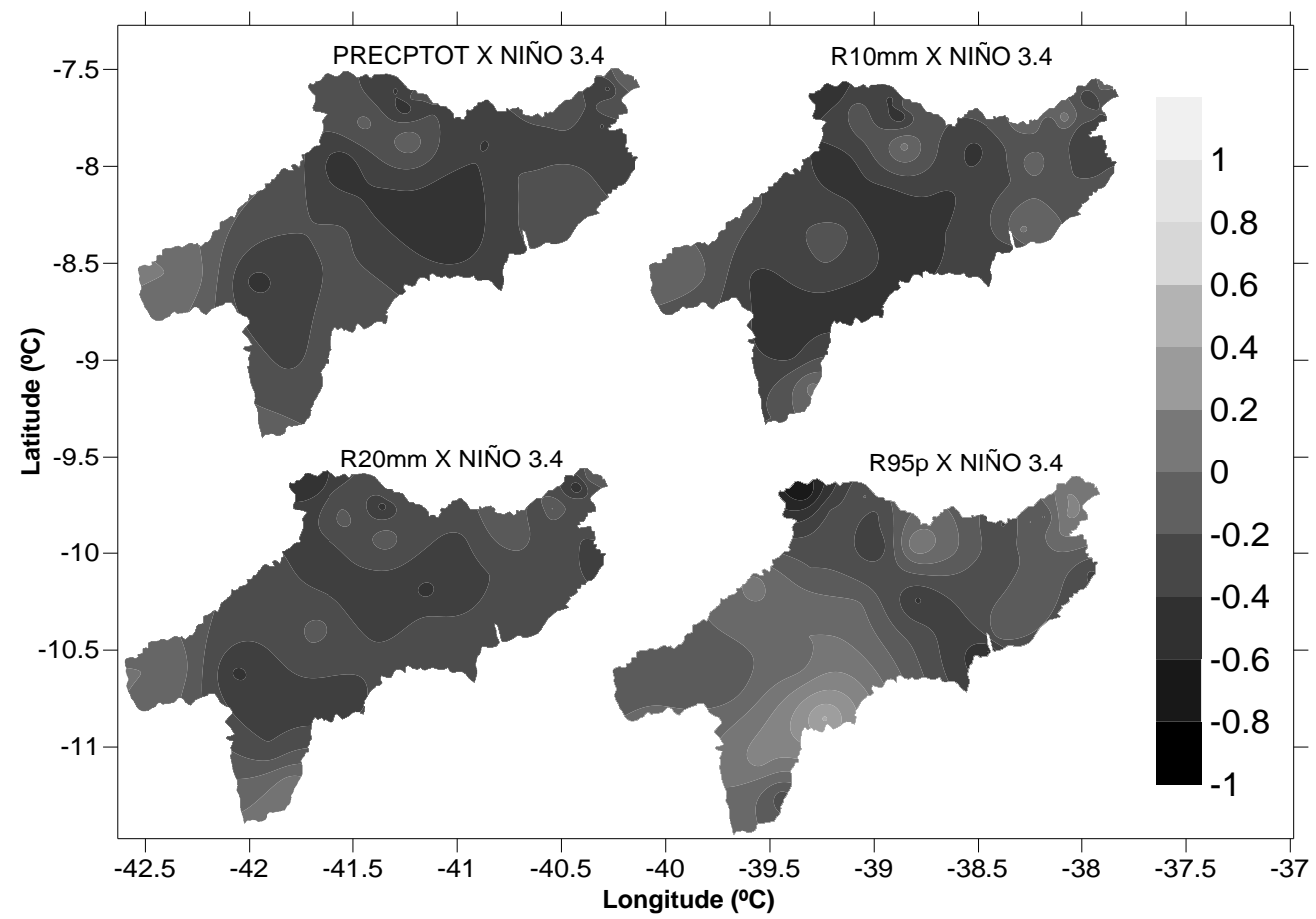

Figura 6 - Correlações entre os índices climáticos PRCPTOT, R10mm, R20mm, R95p e região do oceânico Pacífico Niño 3.4

A TSM da região do Pacífico Niño 4 e a precipitação na área central da bacia apresentam correlação linear negativa, assim como também em pequenos pontos localizados na região do Araripe e no alto Pajeú em Pernambuco. Em relação aos índices climáticos de chuva moderada (R10mm e R20mm), estes também apresentam maior correlação negativa do que positiva, sofrendo influência em grande parte do Submédio, sobretudo o índice R10mm. De forma geral, as maiores correlações negativas foram observadas na área central da bacia, indicando que o aumento da TSM na região do Niño4 também influencia na diminuição da precipitação total nessa área. A Figura 7 apresenta a correlação espacial entre a região Niño4 e os índices climáticos. 


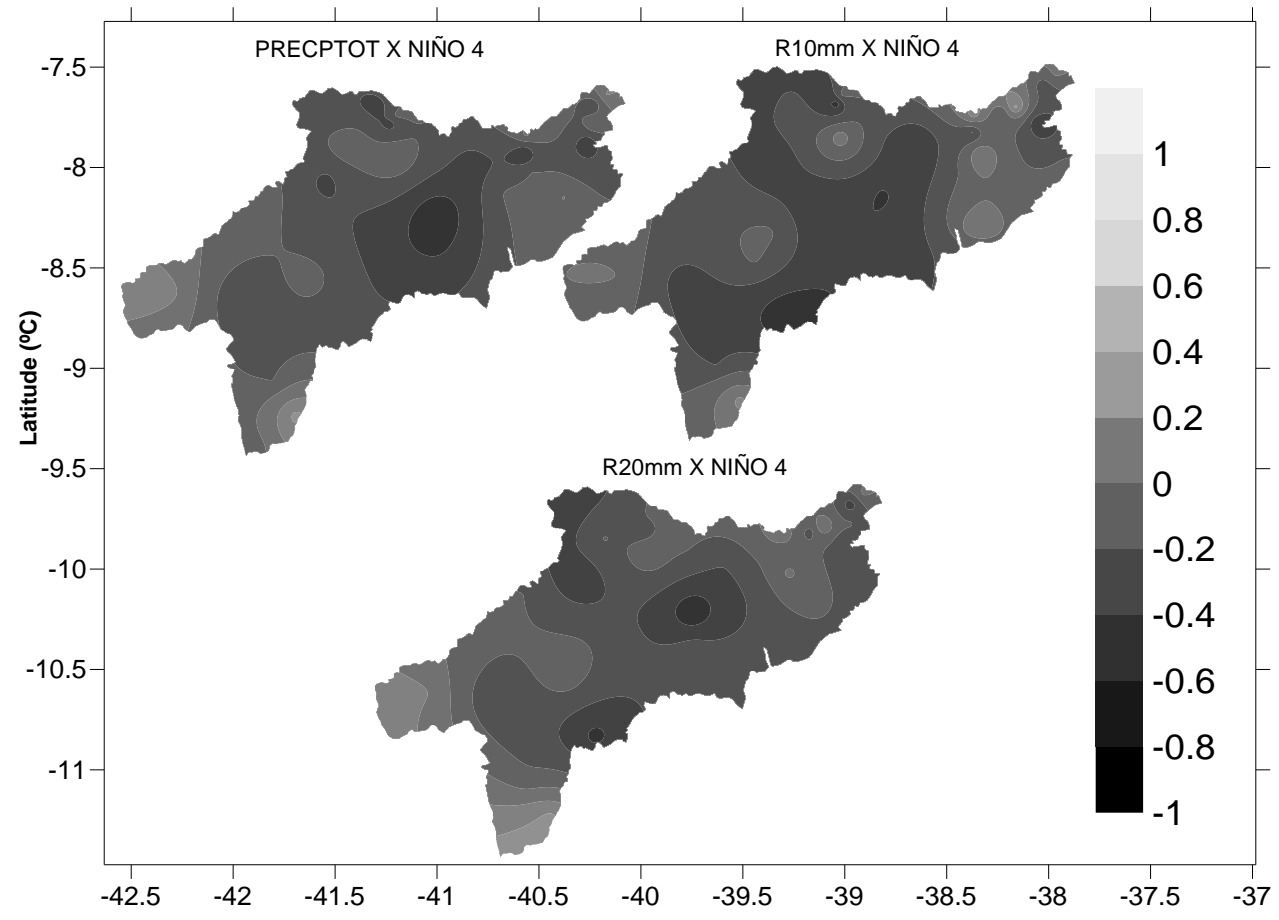

Figura 7 -Correlações entre os índices climáticos PRCPTOT, R10mm e R20mm, e região do oceânico Pacífico Niño 4

Todas as correlações significantes estatisticamente entre os índices climáticos de precipitação total, chuva intensa e dias com chuva moderada com as regiões do oceano Pacífico Equatorial Niño 1+2, Niño3, Niño 3.4 e Niño 4 apresentaram valores negativos, apontando que o aumento da TSM nessas regiões do Pacífico causa a diminuição das chuvas na bacia do Submédio São Francisco, principalmente as áreas de Niño $1+2$ e Niño 3. Silva et al. (2011), encontrou resultados semelhantes em estudo para a região semiárida de Pernambuco, onde constata que as correlações da precipitação com o oceano Pacífico foram negativas para todos os índices estudados, implicando, assim, uma influência negativa nas chuvas do setor semiárido de Pernambuco, como era de se esperar, pois nos episódios El Niño, as águas quentes nesta bacia modificam a circulação de Walker de forma a provocar subsidência troposférica anômala e reduzir as chuvas no Nordeste do Brasil.

Correlações positivas foram encontradas entre o Índice de Oscilação Sul (IOS) e os índices climáticos de precipitação total anual (PRCPTOT), número de dias com chuva moderada (R10mm e R20mm) e dias muito úmidos (R95p), enquanto com o índice de dias secos consecutivos (CDD) foram encontradas correlações negativas (Tabela 2). Estes resultados apresentam padrões divergentes dos encontrados nas demais regiões do Pacífico Equatorial, sendo necessário fazer uma investigação mais aprofundada para compreender realmente as causas desta observação.

Em estudo para a América do Sul, Silva e Silva (2015) também encontraram, para o IOS, sinais contrários aos obtidos para os demais índices climáticos, onde afirmam que valores positivos e negativos indicam, respectivamente, eventos de La Niña e El Niño. Ainda de acordo com as mesmas 
autoras, além do sinal contrário de correlação linear verificado entre a precipitação, observa-se diferença de intensidade do valor de correlação.

O Índice Oceânico Niño (ION) não mostrou correlações com significância estatística com nenhum dos índices climáticos estudados (Tabela 2). A Figura 8 apresenta as correlações entre os índices climáticos que apresentaram significância estatística com o IOS no oceano Pacífico Equatorial.

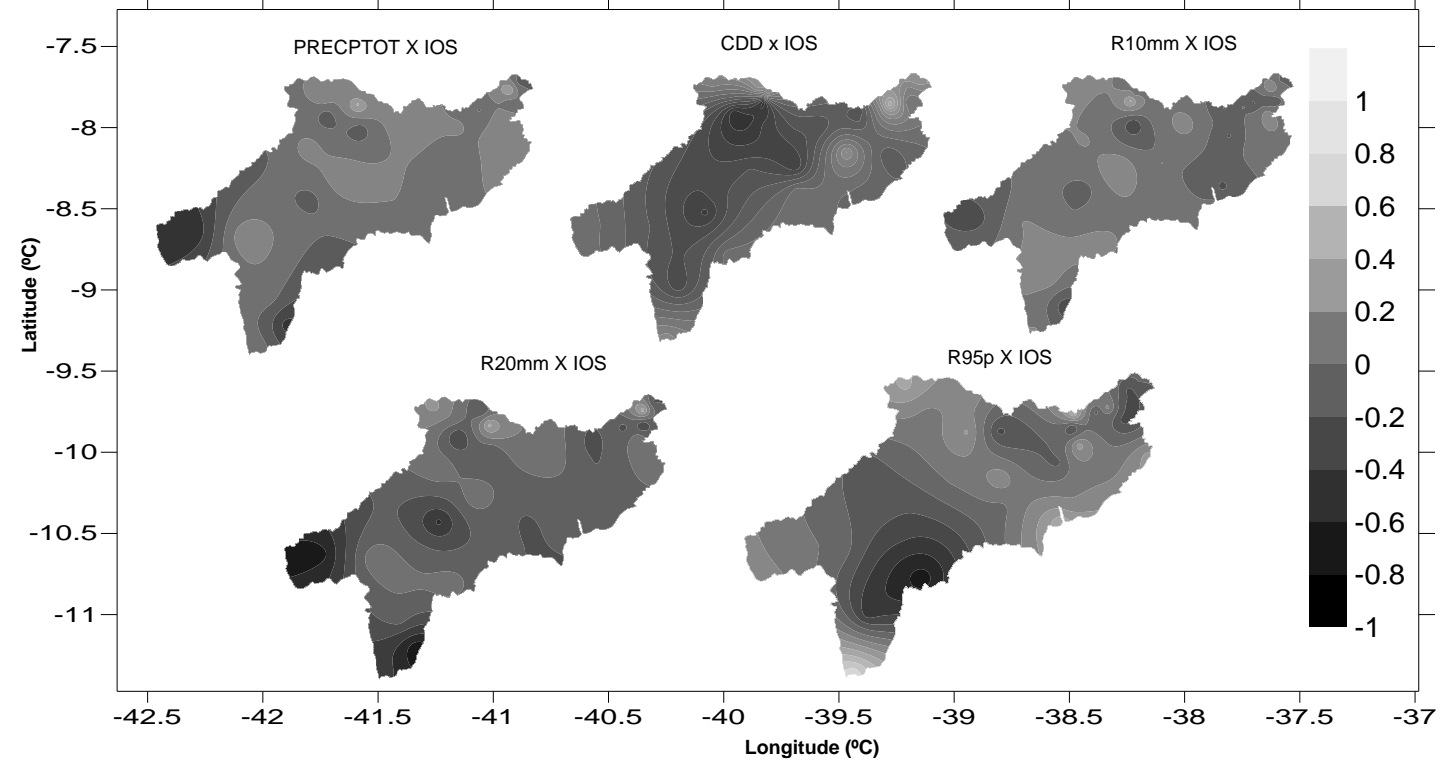

Figura 8 - Correlações entre os índices climáticos PRCPTOT, CDD, R10mm, R20mm e R95p e o índice no oceânico Pacífico IOS

As boas correlações existentes a um nível de significância estatística de 95\% e 99\% para o índice que representa a intensidade diária de chuva (SDII) para as regiões do Atlântico Norte e Sul, respectivamente, assim como a boa correlação de $95 \%$ de significância para os índices R10 e R20 na região do Atlântico Norte podem ser explicados pelas anomalias de TSM, em tais regiões, com atuação do ENOS, por exemplo, Philander (1990) e Moura et al. (2000), mostraram a grande influência do ENOS sobre o clima de diversas partes do globo, incluindo o oceano Atlântico Tropical e o Nordeste do Brasil.

Em relação às correlações negativas entre o Atlântico Norte e Sul e o índice climático de intensidade das chuvas (SDII) Servain (1991) afirma que o gradiente meridional do atlântico tropical de TSM apresenta correlações fortemente negativas com as precipitações da região Norte do Nordeste. 0 gradiente meridional do atlântico tropical constitui então um bom indicador da qualidade da estação chuvosa nessa região, controlando o regime das chuvas no norte do NEB, especialmente em anos de condições neutras sobre o Pacífico. $O$ padrão de anomalias de TSM sobre o atlântico tropical propicia a ocorrência de gradientes meridionais de anomalias de TSM, os quais impactam fortemente na posição latitudinal da ZCIT, modulando assim a distribuição sazonal de precipitação pluviométrica sobre o Atlântico Equatorial, parte norte do Nordeste do Brasil, até a parte central da Amazônia (Nobre and Shukla, 1996; Moura and Shukla, 1981). Marengo et. al. (2011), do mesmo modo afirmam que, particularmente sobre o Brasil, a região do semiárido está entre as mais 
significativamente influenciadas pelas circulações atmosféricas e oceânicas do Atlântico Tropical. O autor afirma ainda que o padrão dipolo no Atlântico Tropical propicia a ocorrência de gradientes meridionais de anomalias de TSM, os quais afetam, sobremaneira, a posição latitudinal da ZCIT, modulando a distribuição sazonal da precipitação pluviométrica sobre o Atlântico Equatorial, na parte Norte do Nordeste do Brasil.

Resultados divergentes foram encontrados por Araújo (2011) em estudo para a Bahia, onde encontrou correlações positivas entre SDII e TNA / TSA, assim como também para a região do Pacífico Niño4. Em geral espera-se uma configuração de dipolo no campo das correlações entre a precipitação da região Nordeste e as anomalias de TSM do Atlântico Tropical. Justifica-se a falta de similaridade entre os resultados, as distintas áreas estudadas embora ambas na região Nordeste, uma localiza-se ao sul da região, enquanto o presente estudo aborda a porção norte da região Nordeste, que possui diferentes períodos chuvosos.

As Figuras 9 e 10 apresentam as correlações entre os índices oceânicos do Atlântico Norte e Sul e os índices climáticos que apresentaram significância estatística.

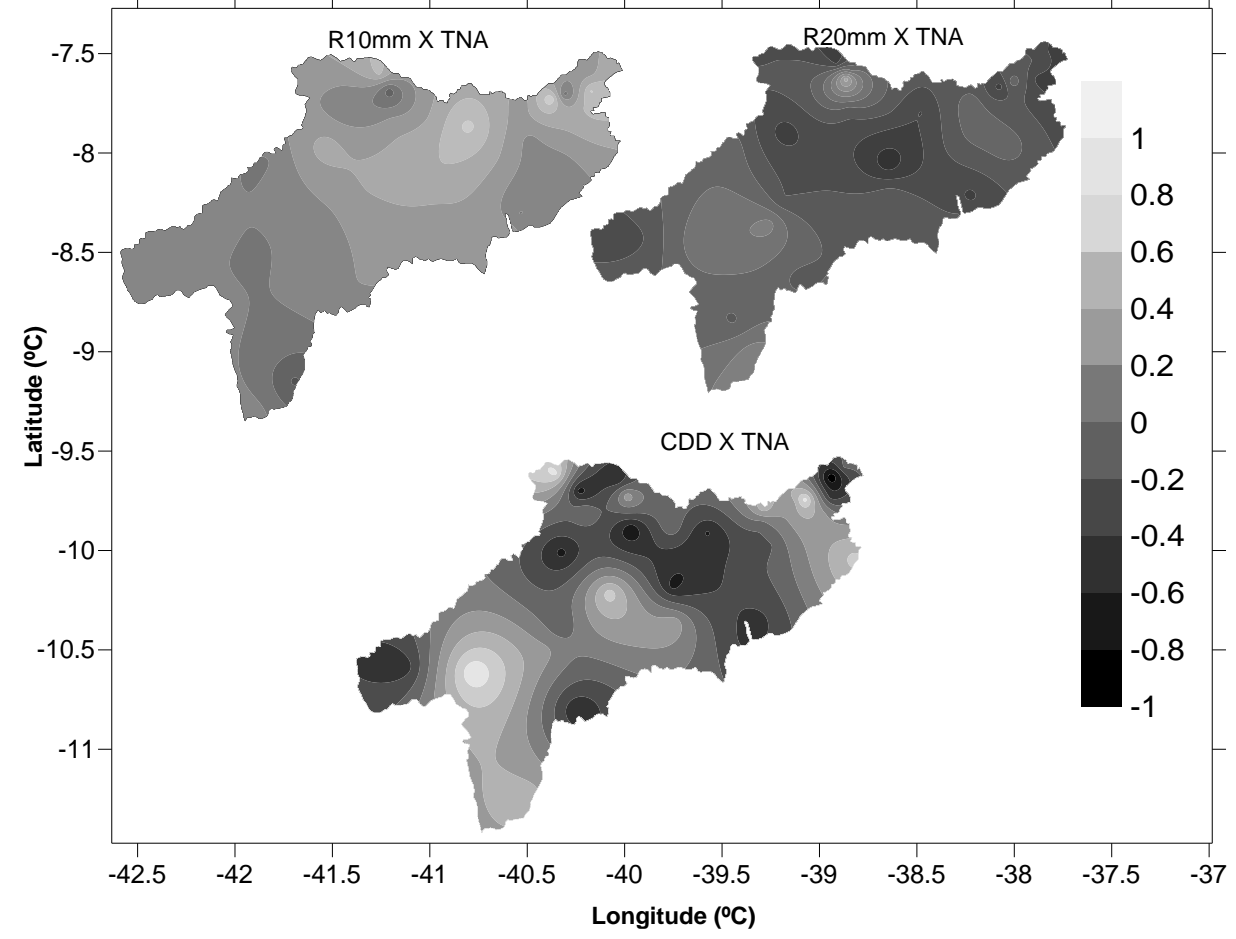

Figura 9 - Correlações entre os índices climáticos R10mm, R20mm e SDII e região do oceânico Atlântico Norte TNA 


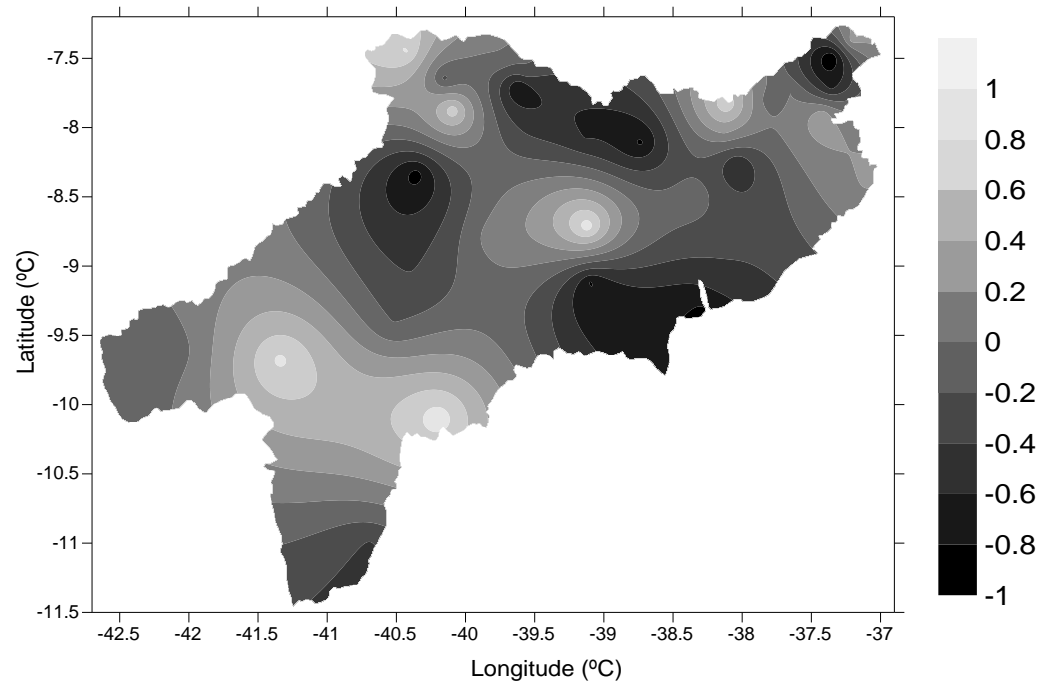

Figura 10 -Correlações entre o índice climático SDII e região do oceânico Atlântico sul TSA

\section{CONCLUSÕES}

Diagnosticou-se que os índices oceânicos observados no oceano Pacífico equatorial têm uma maior influência sobre os índices climáticos dependentes da precipitação em relação aos índices observados no oceano Atlântico, revelando que o fenômeno El Niño/Oscilação Sul tem grande influência no regime de precipitação na bacia do Submédio São Francisco, com redução das chuvas na região.

De forma geral, o aumento da temperatura da superfície do mar observada sobre o oceano Pacífico equatorial, nas regiões do Niño1+2, Niño3, Niño3.4 e Niño4, resultou na redução da precipitação total anual e nas precipitações diárias acima de 10 e $20 \mathrm{~mm}$, cujos resultados são comumente encontrados na bibliografia mundial. Evidencia-se que o aquecimento das águas sobre o Pacífico equatorial, nas regiões do Niño1+2 e Niño3 apresentam uma maior influência na diminuição da precipitação em relação às áreas do Niño3.4 e Niño4, e que estas regiões também induzem a diminuição da intensidade diária das chuvas observadas no Submédio São Francisco.

Os oceanos Atlântico Tropical Norte e Atlântico Tropical Sul também influenciam no comportamento da precipitação na bacia do Submédio São Francisco, principalmente quanto há um aquecimento maior observado no oceano Atlântico Tropical Norte em relação ao Atlântico Sul, induzindo a Zona de Convergência Intertropical posicionar-se mais ao norte da linha do equador e consequentemente na redução da precipitação.

Foram constatados através das correlações entre os índices de extremos climáticos dependentes da precipitação diária para a região do Submédio São Francisco e as anomalias de TSM nos Oceanos Pacífico e Atlântico que as anomalias de TSM nas regiões Niño no Pacifico Equatorial influenciam o comportamento da precipitação, induzindo o aumento dos dias consecutivos secos e diminuição da precipitação total na região do Submédio São Francisco. As correlações estatisticamente significativas apresentadas entre os índices 
climáticos R10, R20 e PRCPTOT nas regiões Niño 1+2, Niño3, Niño3.4 e Niño 4 são todas negativas, diferentemente dos dias consecutivos secos, que apresentou correlação positiva, indicando que um aumento nas TSMs dessas regiões leva a uma diminuição dos dias com chuva moderada e da precipitação total.

\section{REFERÊNCIAS BIBLIOGRÁFICAS}

ANDREOLI, R. V.; KAYANO, M. T.; GUEDES, R. L.; OYAMA, M. D.; ALVES, M. A. S. A Influência da Temperatura da Superfície do Mar dos Oceanos Pacífico e Atlântico na Variabilidade de Precipitação em Fortaleza. Revista Brasileira de. Meteorologia, 19(3): 337-344, 2004.

AlVES, M. A. S.; MACHADO, L. A. T.; GANNABATHULA S. S. Estudo da variabilidade da cobertura de nuvens altas na Amazônia Central. Revista Acta Amazonica. VOL. 37(1) P.71 - 80, 2007.

ALVES, J. M. B., C. A. REPELLI, AND N. G. MELLO. A pré-estação chuvosa do setor norte do Nordeste Brasileiro e sua relaçao com a temperatura dos oceanos adjacentes. Revista Brasileira de Meteorologia, 8, 22-30, 1993.

APAC - AGÊNCIA PERNAMBUCANA DE ÁGUAS E CLIMA. Análise das condições oceânicas. Documento síntese, 2015. Disponível em: http://www.apac.pe.gov.br/down/Analise_das_Condicoes_Oceanicas_Outubro_2 015.pdf. Acessado em: 28 de março de 2016.

ARAGÃO, J. O. R. O Impacto do ENSO e do Dipolo do Atlântico no Nordeste do Brasil. Bull. Inst. fr. études andines. 27 (3): 839-844, 1998.

ARAÚJO, W. S.; BRITO, J. I. B. Índices de tendências de mudanças climáticas para os estados da Bahia e Sergipe por meio de índices pluviométricos diários e sua relação com TSM do Pacífico e Atlântico. Revista Brasileira de Meteorologia, v.26, n.4, 541 - 554, 2011.

ASSAD, E. D. et al. Impacto das Mudanças Climáticas no Zoneamento Agroclimático do Café no Brasil. Pesquisa Agropecuária Brasileira. Brasília, v.39, n.11, 2004.

CHANG, Y.; LEE, M. A.; LEE, K. T.; SHAO, K. Adaptation of fisheries and mariculture management to extreme oceanic environmental changes and climate variability in Taiwan. Marine Policy, v. 38, 476-482, 2013.

CHAPMAN, S. C.; STAINFORTH, D. A.; WATKINS, N. W.On estimating local longterm climate trends. Philosophical transactions of the royal society. v. $371, \mathrm{n}$. $1991,2013$.

CLIMANÁLISE; Boletim de Monitoramento e Análise Climática. Edição Especial Comemorativa De 10 Anos. Outubro de 1996.

DIAZ A.F., STUDZINSKI, C.D., MECHOSO, C.R., Relationships between precipitation anomalies in Uruguay and southern Brazil and sea surface temperature in the pacific and atlantic oceans. Journal of Climate, Boston, vol. 11 , n. 2, pp. 251-271, 1998. 
ENFIELD, D.B., A.M. MESTAS, D.A. MAYER, AND L. CID-SERRANO. How ubiquitous is the dipole relationship in tropical Atlantic sea surface temperatures? JGR-O, 104, 7841-7848, 1999.

FERREIRA, P.S., GOMES, V.P., GALVÍNCIO, J.D., SANTOS, A.M., SOUZA, W.M., 2017. Avaliação da tendência espaço-temporal da precipitação pluviométrica em uma região semiárida do estado de Pernambuco. Revista Brasileira de Climatologia 21, 113-134.

FERREIRA, P. S.; SOUZA, W. M.; SILVA, J. F.; GOMES, V. P. Variabilidade Espaço-Temporal das Tendências de Precipitação na Mesorregião Sul Cearense e sua Relação com as Anomalias de TSM. Revista Brasileira de Meteorologia, v. 33, n. 1, 141-152, 2018.

FIGUEIREDO FILHO, D.; JÚNIOR, SILVA J.A. Desvendando os Mistérios do Coeficiente de Correlação de Pearson (r). Revista Política Hoje, v. 18, n. 1, 2009.

GRASSI, B.; REDAELLI, G.; VISCONTI, G. Arctic Sea Ice Reduction and Extreme Climate Events over the Mediterranean Region. Journal of Climate. V. 26, 10101-10110, 2013.

INTERGOVERNMENTAL PANEL ON CLIMATE CHANGE - IPCC. Climate Change The Physical Science Basis. Contribution of Working Group I to the Fourth Assessment Report of the IPCC. Cambridge University. Press, Cambridge, 2007.

IPCC - Intergovernmental Panel on Climate Change. Summary for policymakers. Climate Change 2013: The Physical Science Basis, T. F. Stocker et al., Eds., Cambridge University Press, 2013.

KAYANO, M. T.; RAO, V. B.; MOURA, A. D. Tropical circulations and the associated rainfall anomalies during two contrasting years. Journal of Climatology, v.8, p.477-488. 1988.

KOCH, H.; SILVA, A. L. C. ; AZEVEDO, J. R. G. ; SOUZA, W. M.; KÖPPEL, J. ; SOUZA JUNIOR, C. B.;LIMA BARROS, A. M. ; HATTERMANN, F. F. Integrated hydro- and wind power generation: a game changer towards environmental flow in the Sub-middle and Lower São Francisco River Basin?. Regional Environmental Change. , v.1, p.1 - 16, 2018.

KOUSKY, V. E.; KAYANO, M. T.; CAVALCANTI, I. F. A. A review of the Southern oscillation: oceanic-atmosphericcirculationchangesandrelatedrainfallanomalies. Tellus, v.36A, p.490-504, 1984.

MARENGO. J. A. O futuro clima do Brasil. REVISTA USP, São Paulo, n. 103, p. 25-32, 2014.

MAGAlHÃES, M. N; LIMA, A. C. P. Noções de Probabilidade e Estatística. 7 ed. São Paulo: EDUSP, 2010.

MENEZES, H.E.A.; BRITO, J.I.B.; SANTOS, C.A.C.; SILVA, L.L. A relação entre a temperatura da superfície dos oceanos tropicais e a duração dos veranicos no estado da Paraíba. Revista Brasileira de Meteorologia, v. 23, p.152-161, 2008.

MORANDO, R.; SILVA, A. O.; CARVALHO, L. C.; PINHEIRO, M. P. M. A. Déficit hídrico: efeito sobre a cultura da soja. Journal of Agronomic Sciences, Umuarama, v.3, n. especial, p.114-129, 2014. 
MOURA, B. A. G.; ARAGÃO, J. O. R.; LACERDA, F. F.; PASSAVANTE, J. Z. O. Relação entre a precipitação no setor leste do Nordeste do Brasil e a temperatura da superfície nos oceanos Atlântico (área do dipolo) e Pacífico. Revista Brasileira de Engenharia Agrícola e Ambiental, v.4, n.2, p.247-251. 2000.

MOURA, G. B. A.; ARAGÃO, J. O. R.; MElO, J. S. P.; SILVA, A. P. N.; GIONGO, P. R.; LACERDA, F. F. Relação entre a precipitação do leste do Nordeste do Brasil e a temperatura dos oceanos. Revista Brasileira de Engenharia Agrícola e Ambiental v.13, n.4, p.462-469, 2009.

MOURA, G. B. A; ARAGÃO, J. O R.; LACERDA, F. F.; PASSAVANTE, J. A. O. Relação entre a precipitação no setor leste do Nordeste do Brasil e a temperatura da superfície nos oceanos Atlântico e Pacífico. Revista Brasileira de Engenharia Agrícola e Ambiental, v.4, n.2, p.247-251, 2000.

PBMC: Contribuição do Grupo de Trabalho 2 ao Primeiro Relatório de Avaliação Nacional do Painel Brasileiro de Mudanças Climáticas. Sumário Executivo do GT2. PBMC, Rio de Janeiro, 2013.

RAMOS, A.R.D; BORGES, C.K.; SOUZA, L.H.G.; SANTOS, C.A.C.; Índices de Extremos Climáticos para a região de Manaus-AM $E$ suas relações com anomalias de TSM. In: Anais IV Simpósio Internacional de Climatologia, João Pessoa, 2011.

RODRIGUES, L. O., SOUZA, W. M., COSTA, V. S. O., PEREIRA, M. L. T. Influência dos eventos de El Niño e La Niña no regime de precipitação do Agreste de Pernambuco. Revista Brasileira de Geografia Física. v.10, n.6 (2017), p. 1995-2009.

SANT'ANNA NETO, J. L. Decálogo da climatologia do Sudeste brasileiro. Revista brasileira de climatologia. n. 1, 2005.

SANTOS, C. A. C.; NEALE, C. M. U.; RAO, T. V. R.; SILVA, B. B. Trends in indices for extremes in daily temperature and precipitation over Utah, USA. International Journal of Climatology, n. 31, 2011

SANTOS, C.A.C; SATYAMURTY, P.; SANTOS, E. M. Tendências de índices de extremos climáticos para a região de Manaus-AM. 2012. Revista Acta Amazônica. v. 42, p. 329 - 336, 2012.

SELVEY L. A.; RUTHERFORD, S.; DODDS, J.; DWYER, S.; ROBINSON, S. M. The impact of climate-related extreme events on public health workforce and infrastructure - how can we be better prepared? Australian and New Zealand Journal of Public Health, v. 38, n. 3, 2014

SERVAIN, J. Simple Climatic Indices for the Tropical Atlantic Ocean and Some Applications. Journal of Geophysical Research, v. 96, n. C8, 1991.

SILVA, E. R. L. G.; SILVA, M. E. S. Memória de eventos ENOS na precipitação da América do Sul. Revista do Departamento de Geografia - USP, v. 30, 2015.

SILVA, A. P. N.; MOURA, G. B. A.; GIONGO, P. G.; MEDEIROS, S. R. R. Correlação entre as Temperaturas da Superfície do Mar e a quantidade da precipitação na estação chuvosa no nordeste do estado de Pernambuco. Revista Brasileira de Meteorologia, v.26, n.1, 149 - 156, 2011. 
SOBRAL, M. C.; MONTENEGRO, S. M. G. L.; OliveiRA, R. M. C. M.; MELO, M. G. S. Institucionalidade da interdisciplinaridade na gestão de recursos hídricos no Brasil. In: Arlindo Philippi Jr; Valdir Fernades; Roberto C. S. Pacheco. (Org.). Ensino, pesquisa e inovação: desenvolvendo a interdisciplinaridade. 1ed.Barueri: Manole, v. 1, 2017.

SOBRAL, M. C; ASSIS, J. M. O.; OLIVEIRA, C. R.; SILVA, G. M. N.; MORAIS, M. CARVALHO, R. M. C. Impacto das Mudanças Climáticas nos recursos hídricos no Submédio da bacia hidrográfica do rio São Francisco - Brasil. Revista Eletrônica do Prodema - REDE, v 12, n. 03, 2018.

SATYAMURTY, P., NOBRE, C.A., SILVA DIAS, P. L. South America. In: Meteorology of the Southern Hemisphere. Boston: A.M.S., v. 27, 1998. p.119139.

STOCKER, T. F. Climate Change. The Physical Science Basis. Working Group I Contribution to 476 the Fifth Assessment Report of the Intergovernmental Panel on Climate Change-Abstract for decision-makers.477 Cambridge University Press, Cambridge, United Kingdom and New York, NY, USA, 29 pp, 2013.

VARGAS-AMELIN, E.; PINADO, P. The challenge of climate change in Spain: Water resources, agriculture and land. Journal of Hydrology, v. 518, p. 243249, 2014.

YOU, Q.; KANG, S.; AGUILAR, E.; PEPIN, N.; FLUGEL, W.; YAN, Y.; XU, Y.; ZHANG, Y.; HUANG, J. Changes in daily climate extremes in China and their connection to the large scale atmospheric circulation during 1961-2003. Climate Dynamics, n. 36, 2011.

YILMAZ, A. G.; HOSSAIN, I.; PERERA, B. J. C. Effect of climate change and variability on extreme rainfall intensity-frequency-duration relationships: a case study of Melbourne. Hydrology and Earth System Sciences. V. 18, 4065-4076, 2014.

ZHANG, Y., WANG, J. C., JING, J. H., SUN, J. C. Response of groundwater to climate change under extreme climate conditions in North China Plain. Journal of Earth Science. V.25, China, 612-618, 2014. 